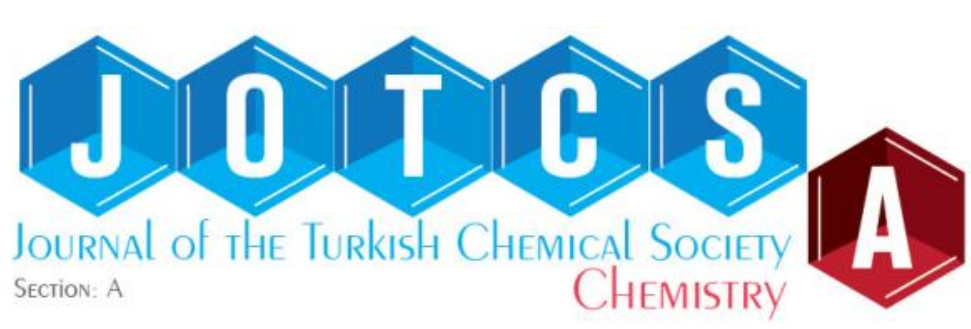

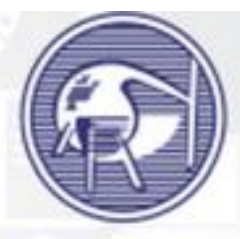

TURKISH

CHEMICAL SOCIETY

\title{
Removal of Zinc from an Aqueous Solution Using Micellar-Enhanced Ultrafiltration (MEUF) with Surfactants
}

\author{
Deniz ŞAHİN TAŞ
}

Gazi University, Faculty of Science, Department of Chemistry, 06500, Ankara, TURKEY

\begin{abstract}
In the present study, the optimum conditions have been investigated for the separation of $\mathrm{Zn}^{2+}$ ions from aqueous solution by micellar enhanced ultrafiltration (MEUF). For this purpose, the best conditions for the concentration of surface active agent in the feed solution (sodium dodecyl sulfate, SDS), cetyltrimethylammonium bromide (CTAB), triton-X-100 (TX100)), filtering pressure, stirring rate, and for the membrane porosity have been determined. It was found that the filtering pressure has a significant effect on the permeate flux but a relatively insignificant impact on rejection of $\mathrm{Zn}^{2+}$. Permeate flux increased linearly with increasing pressure, ranging from $0.32 \mathrm{mLmin}^{-1} \mathrm{~m}^{-2}$ at 3 bar to $0.72 \mathrm{mLmin}^{-1} \mathrm{~m}^{-2}$ at 4 bar. The results showed that by adding SDS anionic surfactant, the permeate flux and the removal efficiency of zinc increased. Best results in terms of zinc rejection coefficient is $97.5 \%$ at $5.0 \mathrm{x}$ $10^{-4} \mathrm{M}$ zinc concentration, $1.0 \times 10^{-2} \mathrm{M}$ SDS concentration $(\sim \times 8 \mathrm{cmc})$, stirring rate $500 \mathrm{rpm}$ and transmembrane pressure 4 bar.
\end{abstract}

Keywords: Micellar Enhanced Ultrafiltration, SDS, CTAB, TX100, Zinc.

Submitted: January 31, 2017. Accepted: February 24, 2018.

Cite this: Şahin Taş D. Removal of Zinc from an Aqueous Solution Using Micellar-Enhanced Ultrafiltration (MEUF) with Surfactants. JOTCSA. 2018;5(2):691-700.

DOI: http://dx.doi.org/10.18596/jotcsa.288933.

*Corresponding author. E-mail: dennoka1k@hotmail.com. 


\section{INTRODUCTION}

Zinc is a trace element known to be an essential nutrient for life. It plays an important role in biological functions; however, if it is in excess, it has major effects on the human body, including abdominal pain, vomiting, nausea, cramps, cardiac irregularities, and increase the risk for development of an autoimmune disease, between others $(1,2)$. The heavy metal toxicity effects is highly dependent on the metal's chemical form. Generally, toxicities of aquo-ionic forms of metals are assumed to be more than those of the bound into particles or organic compounds. Zinc is found naturally in water. Industrial wastewaters with dissolved zinc compounds is released from battery production industries, galvanic industries, the fertilizer industry etc. Zinc compounds are widely used in industry. Zinc chloride is applied for dry cell batteries and paperparchment production, zinc oxide used in production of creams, paints and catalysts, and zinc sulfate is especially applied as a fertilizer ingredient. The main source of $\mathrm{Zn}$ in the surface waters is from zinc leakages zinc pipes and/or rain pipes, consequential to the circulation of carbon-rich water. Car tires containing zinc and motor oil from zinc tanks which releases zinc compounds on the roads. Other source of zinc into water surface is use of fungicides and insecticides and zinc may be emitted from chemical waste dumps and landfills, or from dredge mortar $(3,4)$.

Several different techniques have been developed for use in removal of zinc from waters, such as chemical precipitation, ion-exchange, adsorption, coagulation-flocculation, flotation and electrochemical methods (5). These methods present deficiencies such as, quite energy intensive and operating costs. The main inconvenience of chemical precipitation is the formation of hydroxide precipitate and further, necessity of this compound disposal. Ion-exchange and adsorption are preferred methods for the purification of diluted effluents due to limited adsorption/ion exchange capacity. To overcome the aforementioned problems, a micellar enhanced ultrafiltration (MEUF) system was introduced. In this process, small pollutants are bound (for ionic pollutants) or solubilized (for organic pollutants) in large surfactant micelles which can be separated by ultrafiltration membranes with larger pore size. This process was studied for the removal of metal ions from dilute aqueous streams by researchers (6-10). Scamehorn et al. $(11,12)$ proposed that MEUF was very effective in removing multivalent metal ions and toxic organics simultaneously from industrial wastestreams with the use of anionic synthetic surfactants like sodium dodecyl sulfate. They conclude that system performance can be improved by reducing the feed concentration of metal ions, and/or increasing the surfactant concentration, transmembrane pressure, and membrane pore size (up to $5000 \mathrm{MWCO}$ ). The permeate concentration decreases with use of surfactant mixtures (non-ionic and anionic surfactants) and increases with addition of monovalent salts such as $\mathrm{NaCl}$. The rejection rate increases with the following metal types: $\mathrm{Ca}^{2+} \mathrm{Cu}^{2+} \mathrm{Zn}^{2+} \mathrm{Cd}^{2+}$. In the removal of copper, zinc, and cadmium, rejection rates of $99+\%$ were observed. Akita used in MEUF to remove zinc ions 
from aqueous solutions (up to $0.5 \mathrm{mmol} / \mathrm{L}$ ) include CPC, PONPE10 and SDS, the $\mathrm{Zn}^{2+}$ rejection were near to $0,8.7$, and $84.8 \%$ (13).

In this work, MEUF was used to remove zinc from aqueous solutions using the ultrafiltration membrane. The effects of some important parameters on metal percent rejection and permeate flux were investigated. These parameters include filtering pressure, the concentration of surface active agent, stirring rate, and for the membrane porosity. These results can be helpful in achieving the practical application of this process.

\section{MATERIALS AND METHOD}

\section{Materials}

All the chemicals used were of analytical reagent grade. Deionized water (DI) was used throughout the experiments. The stock solution of $\mathrm{Zn}$ (II) (1000 $\mathrm{mg} \mathrm{L}^{-1}$ ) was prepared by dissolving an appropriate amount of $\mathrm{Zn}\left(\mathrm{NO}_{3}\right)_{2} \cdot 6 \mathrm{H}_{2} \mathrm{O}$ (Merck) in DI water. SDS (Merck), CTAB (Aldrich), TX100 (Riedel) were used as supplied. The surfactant stock solutions $(2 \%, \mathrm{v} / \mathrm{v})$ were prepared by dissolving $2 \mathrm{~mL}$ of concentrated solution in deionized water.

\section{Method}

All experiments were carried out in a batch-stirred ultrafiltration cell (Amicon 8050, Millipore, USA; Figure 1). Two organic regenerated cellulose membranes with a molecular weight cut-off (MWCO) 1000 and 5000 Da obtained from Millipore were used for all the MEUF experiments. A new membrane was used for each test except in cases where the permeability of the used membrane could be fully recovered. A $30 \mathrm{~mL}$ feed solution was charged into the cell. The ultrafiltration was carried out at room temperature $\left(28 \pm 2^{\circ} \mathrm{C}\right)$. Pressurized air was used to maintain the transmembrane pressure. The stirred cell was placed on a magnetic stirrer. The stirring speed was measured with a digital tachometer (Optic DT-838).

The first $5 \mathrm{~mL}$ of the permeate was discarded. The ultrafiltration was continued until $5 \mathrm{~mL}$ of sample remained in the retentate. $20 \mathrm{~mL}$ of permeate was collected and analyzed.
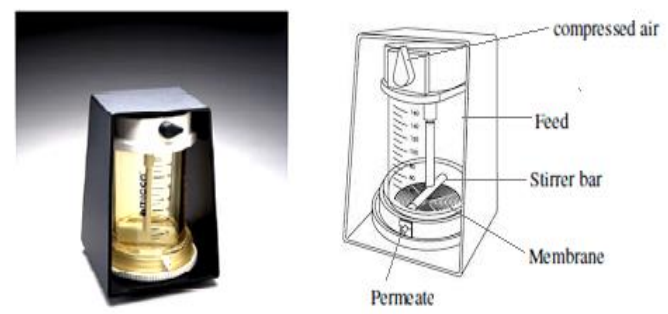

Figure 1. UF cell used in the experiments. 
Şahin Taş D, JOTCSA. 2018; 5(2): 691-700.

Surfactant concentration in the permeate samples $[S]_{p}$ was determined via surface tension measurements. The plot of surface tension (ordinate) as a function of the logarithm of surfactant concentration (abscissa) was constructed to determine the $[\mathrm{S}]_{\mathrm{p}}$.

Concentrations of $\mathrm{Zn}$ (II) ions in the feed and permeate were determined by flame atomic absorption spectrometry (VARIAN 240 FS, FAAS). The operating conditions were as follows: wavelength: $213.9 \mathrm{~nm}$, lamp current: $7 \mathrm{~mA}$, bandpass: $1.0 \mathrm{~nm}$ and fuel flow rate: $1.2 \mathrm{Lmin}^{-1}$. Deuterium lamp background correction was used. Determinations were performed in triplicate.

\section{RESULTS and DISCUSSION}

\section{Effect of the surfactant concentration and membrane porosity}

Penetration of the surfactant through the membranes to permeate flux is one of the main disadvantages of the MEUF process (14). Due to this disadvantage, the retention of the surfactant was investigated without addition of metal ion in the filtrated solution. For this purpose, the filtration of the surfactant solutions was performed. The results of ultrafiltration of aqueous surfactant solutions of different concentrations with regenerated cellulose membranes (1000-5000 Da) are shown in Table 1. The performance of the membranes is indicated in terms of initial surfactant retention and permeation rate during batch ultrafiltration (15). A general increase in surfactant retention with increase in feed concentration $[S]_{i}$ is observed during ultrafiltration with each membrane.

Concentration below critical micelle concentration (CMC), micelles are not absent so surfactant will be present as monomers. These monomers are able to form complex with the metal ions which can easily pass through the membrane. At smaller concentrations, due to the membrane effect, monomer attracts towards membrane and either adsorbed in pores or amasses on the membrane surface on a gel layers (16). When surfactant concentration increased up to CMC, the micelle formation provides binding sites to metal ions on the surface and the rejection of ions increases (17). On further increase in the concentration of surfactant, the formed micelles break into smaller aggregates of low aggregation size. These aggregates effectively bind the metal ions, after concentration of the metal ion also increase and pass through the membrane towards the permeate side $(18,19)$. Examination of the literature shows that the concentration of a surfactant in solution increases after the CMC and a second CMC occurs (20). These, undoubtly, reflect change in size, shape, polydispersity and degree of concentration binding to binding to the micelle and also change rate of hydration (21). A second CMC exists where the aggregates gain positional order due to increased electrical repulsions among the micelles (22). According to Porte et al (23), the second CMC arises from a sphere to rod transition of the micelle geometry. 
In our preliminary experiments, we determined to find the CMC of surfactants (not shown). CMCs for SDS, CTAB, and TX-100 using surface tension technique (our propositional method) were $8.1 \times 10^{-3}, \quad 1.14 \times 10^{-3}$ and $3.6 \times 10^{-4} \mathrm{~mol} \mathrm{~L}^{-1}$, respectively. The permeate surfactant concentration were approximately equal to the CMCs for SDS and CTAB but about 2 times lower than CMC for TX-100. The difference can be explained in terms of the relative size of the TX-100 micelles. The CMC of TX-100 is lower and the aggregation number of micelles is greater (Table 1), so there are larger TX-100 micelles in a lower TX-100 concentration and the concentration in the retentate of TX-100 micelles may increase. The structural difference of used surfactants depends on theirs hydrophilicity as listed in Table 2, and an increase aggregation number caused by the decrease in hydrophilic chain length $(24,25)$ results in increasing the number of $\mathrm{Zn}^{2+}$ binding sites.

Table 1. Ultrafiltration of surfactant solutions.

\begin{tabular}{|c|c|c|c|c|c|c|}
\hline \multirow{3}{*}{$\begin{array}{l}\text { [SDS] } \\
\times 10^{2}\end{array}$} & \multirow{3}{*}{$\begin{array}{r}\text { [CTAB] } \\
\times 10^{3}\end{array}$} & \multirow{3}{*}{$\begin{array}{c}\text { [TX100] } \\
\times 10^{3}\end{array}$} & \multicolumn{2}{|c|}{$[S]_{\mathrm{p}} \times 10^{4}$} & \multirow{2}{*}{\multicolumn{2}{|c|}{$\begin{array}{l}\text { Permeation Rate } \\
\qquad\left(\mathbf{m L x m i n}^{-1}\right)\end{array}$}} \\
\hline & & & \multirow[b]{2}{*}{$\begin{array}{c}1000 \\
\mathrm{Da}\end{array}$} & \multirow[b]{2}{*}{$5000 \mathrm{Da}$} & & \\
\hline & & & & & $1000 \mathrm{Da}$ & $5000 \mathrm{Da}$ \\
\hline 2.00 & & & 21.00 & 29.00 & 0.361 & 0.750 \\
\hline 5.00 & & & - & 33.00 & - & 0.670 \\
\hline 10.00 & & & 38.00 & 43.00 & 0.273 & 0.550 \\
\hline 20.00 & & & - & 52.00 & - & 0.360 \\
\hline \multirow[t]{11}{*}{30.00} & & & 52.00 & 60.00 & 0.070 & 0.170 \\
\hline & 2.00 & & 4.72 & 4.81 & 0.300 & 0.630 \\
\hline & 5.00 & & 4.75 & 4.85 & 0.294 & 0.610 \\
\hline & 10.00 & & 4.75 & 4.90 & 0.285 & 0.600 \\
\hline & 20.00 & & 4.79 & 4.90 & 0.280 & 0.540 \\
\hline & 30.00 & & 4.80 & 4.95 & 0.275 & 0.530 \\
\hline & & 0.50 & 0.64 & 0.94 & 0.350 & 0.630 \\
\hline & & 1.25 & - & 1.03 & - & 0.620 \\
\hline & & 2.50 & 0.67 & 1.12 & 0.347 & 0.600 \\
\hline & & 5.00 & - & 1.19 & - & 0.600 \\
\hline & & 7.50 & 0.77 & 1.30 & 0.346 & 0.600 \\
\hline
\end{tabular}

Further increase in the membrane porosity, up to $5000 \mathrm{Da}$, resulted in a marginal increase in the permeation rate. Therefore, 5000 Da was selected as membrane porosity for further experimental works.

Table 2. Characteristics of selected surfactants.

\begin{tabular}{|c|c|c|c|c|c|c|}
\hline Name & $\begin{array}{l}M^{a} \\
(\mathrm{~g} / \mathrm{mol})\end{array}$ & $\begin{array}{l}\text { CMC } \\
(\mathrm{mM})\end{array}$ & HLB $^{b}$ & $\begin{array}{l}\text { Aggregation } \\
\text { numberc }\end{array}$ & $\begin{array}{l}\text { MW of } \\
\text { micelle }^{d} \\
(\mathrm{~g} / \mathrm{mol})\end{array}$ & $\underset{e}{\text { Solubility }}$ \\
\hline SDS & 288 & 8.1 & 40 & 80 & 23040 & $\mathrm{~s}$ \\
\hline CTAB & 364 & 1.14 & - & - & - & $\mathrm{s}$ \\
\hline TX-100 & 625 & 0.36 & 13.5 & 140 & 87500 & $\mathrm{~s}$ \\
\hline
\end{tabular}


a MW: An average molecular mass, b HLB: hydrophilic-lipophilic balance, ${ }^{c}$ Aggregation number of the micelle, d $\mathrm{MW}$ : molecular mass of the miçelle, e $\mathrm{s}$ means readily soluble in water.

\section{Effect of applied pressure}

The pressure was varied from 3 to 4 bar, because the maximum operating pressure limit is 4 bar in our laboratory systems. The flow rates in different pressure and constant surfactant concentrations (Table 3 ) show same behaviors for each surfactant and help choose the most suitable transmembrane pressure force.

Table 3. Concentration of surfactant in the permeate and permeation rate as a function of applied pressure.

\begin{tabular}{|c|c|c|c|c|c|c|}
\hline \multirow[b]{2}{*}{$\begin{array}{l}\text { Transmembrane Pressure } \\
\text { (Bar) }\end{array}$} & \multicolumn{2}{|c|}{$1.0 \times 10^{-1} \mathrm{M}$ SDS } & \multicolumn{2}{|c|}{$1.0 \times 10^{-2}$ М СТАВ } & \multicolumn{2}{|c|}{$2.5 \times 10^{-3} \mathrm{M}$ TX100 } \\
\hline & 3 & 4 & 3 & 4 & 3 & 4 \\
\hline$[S]_{p} \times 10^{4}$ & 9.53 & 9.60 & 8.33 & 8.40 & 1.10 & 1.12 \\
\hline Permeation Rate $\left(\mathrm{mLxmin}^{-1}\right)$ & 0.32 & 0.72 & 0.34 & 0.75 & 0.46 & 0.89 \\
\hline
\end{tabular}

No significant effect was observed on the permeate surfactant concentration if the pressure was increased from 3 to 4 Bar, but the permeation rate increased slightly. The permeate flux increased linearly with applied pressure at a constant surfactant concentration. This may be due to the fact that the operating pressure between retentate and permeate acts as effective driving force for membrane separation process. The increase of this could overcome the osmotic pressure and the resistance, thereby forcing more solution to filter through the membrane and leading to a higher permeate flux (26-28). At CMC, sites for binding of $\mathrm{Zn}^{2+}$ increased with increasing concentration of micelles near the membrane surface which may contribute to increase in rejection. The pressure can also vary according to the capacity of membrane to withstand $(29,30)$.

\section{Effect of filtration speed}

In order to determine the optimize sampling rate, the filtration speed was varied between 100 and $500 \mathrm{rpm}$, maintaining constant other experimental conditions (Table 4). 
Table 4. Effect of filtration speed on the permeation rate and permeate surfactant concentration.

\begin{tabular}{ccc}
\hline$[\mathrm{S}]_{i}$ & & $2.0 \times 10^{-2} \mathrm{M}$ SDS \\
Stirring Speed $(\mathrm{rpm})$ & 100 & 500 \\
{$[\mathrm{~S}]_{\mathrm{p}} \times 10^{4}$} & 0.30 & 0.28 \\
& & \\
Permeation Rate $\left(\mathrm{mLxmin}^{-1}\right)$ & 0.625 & 0.740 \\
\hline
\end{tabular}

With the increase in the flow rate, velocity and turbulence near the membrane surface also increased. This leads to an increase in mass transfer across the membrane surface and hence an increase in the permeate flux. A filtration flow rate of $500 \mathrm{rpm}$, was the most adequate for the quantitative retention. Permeation rate of $500 \mathrm{rpm}$ was chosen as optimal. Moreover, the maximum permeate flux is achieved by SDS. SDS has higher CMC and lower aggregation number of single SDS micelle than other surfactants as listed in Table 2, so it makes micellization more difficult and deposit fewer micelles in large size surface area of the membrane. Therefore, SDS was selected as surfactant for following experiences.

\section{Ultrafiltration of $\mathrm{Zn}$ (II) ions with addition of surfactant (MEUF process)}

The optimum conditions obtained during experimentation were; pressure: 4 bar, surfactant: SDS, flow rate: $500 \mathrm{rpm}$, and membrane porosity: 5000Da and temperature: $25^{\circ} \mathrm{C}$, at which $>96.0 \%$ of rejection had been observed for the removal of zinc.

The applicability of MEUF method to zinc ions separation was examined by the use of SDS. As observed from the figure the rejection of $\mathrm{Zn}^{2+}$ increased from $10.85 \%$ to $97.5 \%$, when removing the $\mathrm{Zn}^{2+}$ from the feed solution, we used the rejection rate $\mathrm{R}$ expressed as:

$$
R \%=\left(1-\frac{C_{p}}{C_{i}}\right) \times 100
$$

where $C_{\mathrm{i}}$ is the initial concentration of the $\mathrm{Zn}^{2+}$ ion in the feed solution and $C_{\mathrm{p}}$ is the $\mathrm{Zn}^{2+}$ ion concentration in the permeate. 


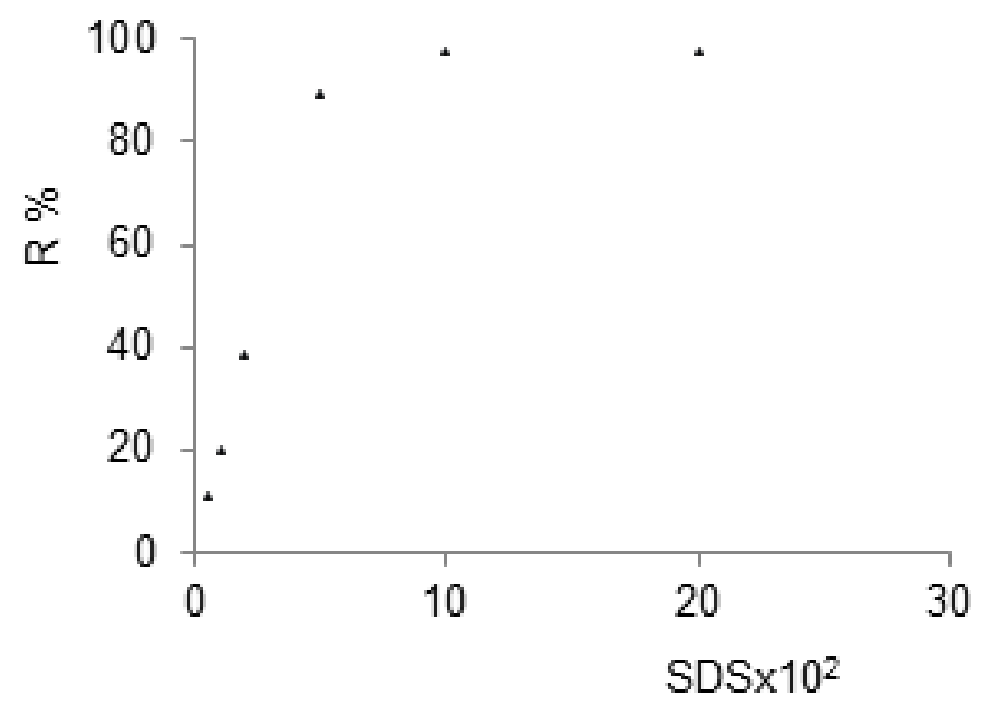

Figure 2. Effect of the initial SDS concentration on the rejection of $\mathrm{Zn}^{2+}$.

Figure 2 shows the variation of the $\mathrm{Zn}^{2+}$ rejection with the initial SDS concentrations ranging from $5.0 \times 10^{-3} \mathrm{M}$ up to $2.0 \times 10^{-2} \mathrm{M}$ at a constant $\mathrm{Zn}^{2+}$ concentration of $5.0 \times 10^{-4} \mathrm{M}$ and a constant pressure of 4 bar. This curve shows an immediate rise in the retention of $\mathrm{Zn}^{2+}$ with the increasing feed SDS concentration, which later reaches a plateau at a higher SDS concentration. The rejection may be attributed to the fact that the number of micelles increased with increase in SDS concentration. When the SDS concentration is below its $\mathrm{cmc}$, micelles not found in the bulk solution and no separation of $\mathrm{Zn}^{2+}$ is expected in theory. When the SDS concentration reaches $\mathrm{cmc}$ level at the concentration polarization layer, many SDS monomers can be present large numbers of big-size micelles at the concentration polarization layer (31).

\section{CONCLUSION}

The MEUF process was successfully applied for removal of $\mathrm{Zn}^{2+}$ ions from aqueous solutions. A regenerated cellulose membrane was used for filtration process, while SDS was used as the surface active agent. The influence of some important parameters including the feed SDS concentration, membrane porosity, operating pressure, and filtration speed was investigated. The results revealed that the permeate flux increased with increasing, to optimal levels, transmembrane pressure and filtration speed. When the initial SDS concentration was the $6 \mathrm{mM}$, high $\mathrm{Zn}^{2+}$ rejection (97\%) was obtained due to concentration polarization phenomena occurring at the membrane/solution interface.

\section{REFERENCES}

1. Goldfrank LR, Goldfrank's Toxicologic Emergencies, 8th Edition, McGraw Hill, New York, 2006.

2. Vega M, Augusto M, Talío MC, Fernández LP. Surfactant Enhanced Chemofiltration of Zinc Traces Previous to Their Determination by Solid Surphase Fluorescence American Journal of Analytical Chemistry, 2011 Dec; 2: 902-908. 
3. Lenntech, www.lenntech.com/periodic/ water/zinc/zinc-and-water.htm

4. Trıvunac K, Sekulıc Z and Stevanovic S. Zinc removal from wastewater by a complexation-microfiltration process. J. Serb. Chem. Soc. 2012; 77(11): 1661-1670.

5. Fu F and Wang Q. Removal of heavy metal ions from wastewaters: A review. Journal of Environmental Management. 2011 Mar; 92(3):407-413.

6. Rahmanian B, Pakizeh M and Maskooki A. Micellar-enhanced ultrafiltration of zinc in synthetic wastewater using spiral-wound membrane Journal of hazardous materials. 2010 Dec; 184(1-3) : 261-267.

7. Scamehorn J, Dunn Jr, Christian S. Simultaneous removal of dissolved organics and divalent metal cations from water using micellar-enhanced ultrafiltration. Colloids and Surfaces, 1989; 35(1): 49-56.

8. Hankins N, Hilal NO, O Ogunbiyi, Azzopardi B. Inverted polarity micellar enhanced ultrafiltration for the treatment of heavy metal polluted wastewater. Desalination, 2005; 185(1-3):185-202.

9. Landaburu-Aguirre J, García V, Pongrácz E, Keiski R. The removal of zinc from synthetic wastewaters by micellar-enhanced ultrafiltration: statistical design of experiments. Desalination. 2009 May; 240(1-3): 262-269.

10. Landaburu-Aguirre J, Pongrácz E, Perämäki, Keiski R. Micellar-enhanced ultrafiltration for the removal of cadmium and zinc: Use of response surface methodology to improve understanding of process performance and optimisation. Journal of Hazardous Materials. 2010 Aug; 180(1): 524-534.

11. Scamehorn, J.F., Ellington, R.T. and Christian, S.D. Removal of Multivalent Metal Cations from Water using Micellar-Enhanced Ultrafiltration, Recent Separation Techniques-IIl, AICE symposium Series 250, p. 48-58 (1986).

12. Scamehom, J.F, Christian, S.D. and Ellington, R.T. Use of Micellar-Enhanced Ultrafiltration to Remove Multivalent Metal Ions from Aqueous Streams. In: Surfactant-Based Separation Process, edited by Scamehorn, J.F. and Harwell, J.H., Surfactant Science Series, Vol. 33, p. 29-51, Marcel Dekker, Inc., New York, NY (1989).

13. Akita S, Takeuchi H, Yang L. Micellar-enhanced ultrafiltration of gold(III) with nonionic surfactant. J. Membr. Sci. 1997; 133(2): 189-194.

14. Staszak K, Redutko B, Prochaska K. Removal of metal ions from aqueous solutions by micellar enhanced ultrafiltration (MEUF). Polish Journal of Chemical Technology 2010; 12(3):62- 65.

15. Shimoda K., In Colloidal Surfactants (Ed). K. Shinoda,T. Nakagava,B. Tamamushi, and T.Isemura, 1963 Chap I , Academic Press, N.Y.

16. Karate VD, Marathe KV. Simultaneous Removal of Nickel and Cobalt From Aqueous Stream by Cross Flow Micellar Enhanced Ultrafiltration. J. Hazard. Mater. 2008; 157 (2-3):464-471.

17. Bade R, Lee SH, Jo S, Lee HS, Lee SE. Micellar enhanced ultrafiltration (MEUF) and activated carbon fibre (ACF) hybrid processes for chromate removal from wastewater. Desalination. 2008; 229(1-3):264273.

18. Danis $U$, Keskinler B. Chromate removal from wastewater using micellar enhanced crossflow filtration. Desalination. 2009; 249(3):1356-136.

19. Yenphan $P$, Chanachai $A$, Jiraratananon R. Experimental study on micellar-enhanced ultrafiltration (MEUF) of aqueous solution and wastewater containing lead ion with mixed surfactants. Desalination. 2010; 253:30-37.

20. Roberts, R.T. and Jones, G.P. Mol. Cryst. Liq. Cryst. Liq. 17, 281 (1972); Lindman, B. and Brun, B.J. Colloid Interface Sci. 42, 388 (1973); BouaaH, K. and Ache. H.J. ibid. 85, 2444 (1981); Klason, T. NMR Studies of Solubilization, hydrocarbon chain motion and the state of water in amphiphile-water systems. The Royal Institute of Technology Stockholm. (1983).

21. Kubota, Y., Kodama, M. and Miura, Second CMC [critical micelle concentration] of an aqueous solution of sodium dodecyl sulfate. IV. Fluorescence depolarization, M. Bull. Chem. Soc. Jpn., 1973; 46: 100-103. 
22. Kale, K. M.; Cussler, E.L. and Evans, Characterization of micellar solutions using surfactant ion electrodes, D.F. J. Phys. Chem., 1980; 84: 593-598.

23. Porte, G., Poggi, Y. Appell, J. and Moret, G. J. Phys. Chem, 1984; 88: 5703-5812.

24. Mackay RA., Solubilization, in: Martin J. Schick (Ed.), Nonionic Surfactants: Physical Chemistry, Surfactant Science Series, M. Dekker Inc., New York, pp. 1987308-314.

25. Mayers $D$, Surfactants in solution: micelle and related association phenomena, in: Surfactant Science and Technology, VCH Publishers Inc., 2008; 1988:104-106.

26. Zeng GM. et al., Micellar-enhanced ultrafiltration of methylene blue from dye wastewater via a polysulfone hollow fiber membrane. J. Membr. Sci. 2010; 310(1-2):149-160.

27. Park SJ, Yoon HH, Song SK. Solubilization and micellar-enhanced ultrafiltration of o-cresol by sodium dodecyl micelles. Korean J. Chem. Engg. 1997; 14: 233-240.

28. Purkait MK, Gupta SD, De S. Resistance in series model for micellar-enhanced ultrafiltration of eosin dye. J. Colloid Interface Sci. 2004; 270(2):496-506.

29. Chhatre AJ, Marathe KV. Dinamic analysis and optimization of surfactant dosage in micellar enhanced ultrafiltration of nickel from aqueous streams. Sep. Sci. Technol. 2006; 41(12):2755-2770.

30. Aguirre JL, Pongracz E, Keiski RL. Separation of cadmium and copper from phosphorous rich synthetic waters by micellar enhanced ultrafiltration. Sep. Purif. Technol. 2011; 81(1): 41-48.

31. Scamehorn JF, Harwell JH. Surfactant-Based Separation Processes Eds. Marcel Dekker, Inc., 1988 p 46. 